\title{
Improved detection of myocardial infarction by emission computed tomography with thallium-201 Relation to infarct size
}

\author{
SHUNICHI TAMAKI, HIROFUMI KAMBARA, KAZUNORI KADOTA, YUKISONO \\ SUZUKI, RYUJI NOHARA, CHUICHI KAWAI, NAGARA TAMAKI, ${ }^{\star}$ KANJI TORIZUKA* \\ From the Third Division, Department of Internal Medicine and Department of Nuclear Medicine, * Faculty of \\ Medicine, Kyoto University, Kyoto, Japan
}

SUMMARY Emission computed tomography with thallium-201 was compared with planar imaging in its ability to detect myocardial infarctions of various sizes four weeks after the onset. Tomography was performed after planar imaging at rest in 160 patients with a first myocardial infarction, in whom infarct size was prospectively estimated by the peak value of creatine kinase activity at the time of the acute episode and in 39 patients without infarction. The planar images and the transaxial, short axial, and long axial tomograms were interpreted qualitatively. Tomography was significantly more sensitive than planar imaging in detecting anterior $(87 \% v 96 \%)$, inferior $(73 \% v 97 \%)$, and non-transmural $(47 \% v 87 \%)$ infarcts. The increased sensitivity was confined to detecting small infarcts as assessed by the peak creatine kinase value $(44 \% v 89 \%$ when peak creatine kinase activity was $\leqslant 1000 \mathrm{IU} / \mathrm{l})$. The overall sensitivity was $96 \%$ for tomography and $78 \%$ for planar imaging. The specificity was similar (92\%) with the two techniques.

Thus emission computed tomography can improve the detection rate of small infarcts that cannot be identified on planar images, by showing the three dimensional distribution of thallium-201, and increases the diagnostic value of thallium-201 scintigraphy.

Thallium-201 myocardial scintigraphy has been extensively used in the detection of myocardial infarction $^{1-3}$ as well as of coronary artery stenosis. ${ }^{4-6}$ Although more sensitive and specific than electrocardiography, the sensitivity of planar imaging for detecting infarction is still not $100 \%,{ }^{378}$ possibly because of the difficulty in detecting small infarcts owing to the geometric constraints of a two dimensional display. ${ }^{910}$ Emission computed tomography with a rotating gammacamera provides tomographic sections with little of the interplanar propagation ${ }^{1112}$ seen in pinhole tomography. ${ }^{1314}$ Although several preliminary studies have suggested that emission tomography is superior to planar imaging in assessing myocardial infarction with thallium-201,15-17 the

Requests for reprints to Dr Chuichi Kawai, The Third Division, Department of Internal Medicine, Kyoto University Hospital, 54 Kawaracho Shogoin, Sakyo-ku, Kyoto, 606 Japan.

Accepted for publication 1 August 1984 advantage of this technique in detecting myocardial infarction has not been adequately studied in a large series of patients. Moreover, it is still not clear how the detection of small infarcts can be improved by tomography. Accordingly, we undertook this prospective study in patients with myocardial infarction in whom infarct size was estimated by enzymatic analysis during the acute episode. We assessed the ability of both planar imaging and emission computed tomography with thallium-201 to detect myocardial infarction four weeks after its onset with particular reference to the infarct size.

\section{Patients and methods}

We studied 160 patients (133 men and 27 women, mean age 58 (range 31-78) years) after their first myocardial infarction documented by a history of typical chest pain lasting one hour or more, the presence of a characteristic pattern of increase in the serum 
creatine kinase activity above normal values, and the appearance of $Q$ waves or the evolution of ST-T changes characteristic of infarction on the electrocardiogram. These patients were selected from consecutive patients admitted to our coronary care unit with acute myocardial infarction between Şeptember 1981 and December 1983 on the basis of the following criteria: (a) a first acute myocardial infarct with neither clinical nor electrocardiographic evidence of a previous infarction; (b) no recurrence of myocardial infarction after the completion of the enzyme assay until the time of the scintigraphic study; and $(c)$ a peak creatine kinase value measured from serial serum determinations.

To evaluate the problem of false positive test results, we studied 39 additional patients without myocardial infarction (29 men and 10 women, mean age 53 (range 42-64) years). These patients were selected on the basis of normal left ventricular function and regional wall motion at cardiac catheterisation. Twenty of these patients had completely normal coronary arteries. The remaining 19 patients had $<75 \%$ narrowing of at least one coronary artery.

Serum creatine kinase activities were determined at four hourly intervals for $\mathbf{4 8}$ hours from the time of admission and every 12 hours for the following 48 hours. The peak value in the serum creatine kinase curve was used as a biochemical estimate for the extent of the acute myocardial necrosis. ${ }^{1819}$ The upper limits of normal for creatine kinase in our laboratory is $80 \mathrm{IU} / 1$ for men and $70 \mathrm{IU} / 1$ for women.

\section{ELECTROCARDIOGRAPHY}

Standard 12 lead electrocardiograms were recorded at the time of admission and at least once daily for the following seven days. Transmural infarction was defined as the development of new pathological ( 0.04 s) $Q$ waves and non-transmural infarction as transient ST-T changes without the subsequent development of $Q$ waves. The electrocardiographic localisation of the transmural infarction was determined according to the criteria of the American Heart Association. ${ }^{20}$ For analysis, anteroseptal and anterolateral transmural infarcts were grouped as anterior, whereas inferior and inferoposterior transmural infarcts were grouped as inferior infarctions.

\section{MYOCARDIAL SCINTIGRAPHY}

Thallium-201 myocardial scintigraphy was performed four weeks after the onset of infarction in all patients with infarction and 1-7 days before or after cardiac catheterisation in the control patients. Images were obtained approximately 10 minutes after an intravenous injection of $71.3 \mathrm{MBq}(2 \mathrm{mCi})$ of thallium-201 at rest using a large field of view gammacamera (Hitachi: Gamma View) equipped with a low energy high resolution parallel hole collimator. Planar views included the anterior, $30^{\circ}, 45^{\circ}$, and $60^{\circ}$ left anterior oblique, and left lateral projections, and 300000 counts were collected for each image.

COMPUTED TOMOGRAPHY

After planar imaging, tomography was performed

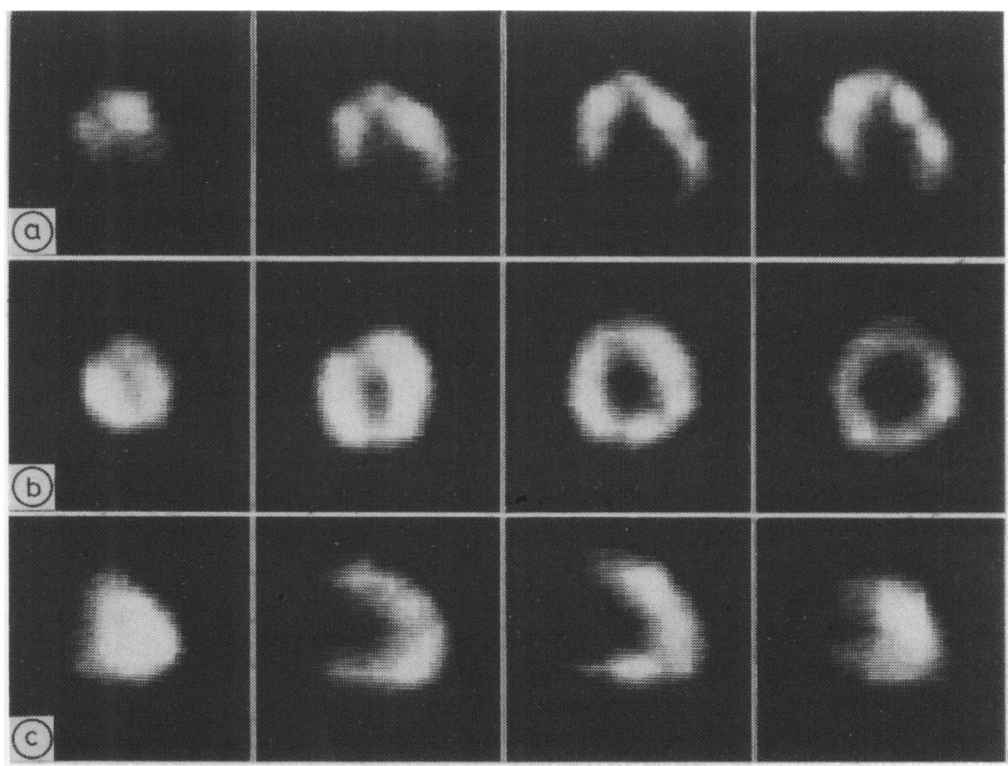

Fig. 1 Normal emission computed tomograms with thallium-201: (a) transaxial images (viewed from below with anterior surface up) from the cranial (left) to the caudal region (right); (b) short axis images (viewed from the apex) from the apex (left) to the base (right); (c) long axis images (viewed from the right anterior oblique projection) from the septal (left) to the lateral region (right). 
using a rotating gammacamera with a high resolution parallel hole collimator supported by a gantry (General Electric: Maxi-400 T) interfaced to a digital computer (DEC: PDP 11/60). The camera rotated from a $45^{\circ}$ left posterior oblique to a $45^{\circ}$ right anterior oblique position of the patient so that data from only the anterior half of the heart were collected. A total of 32 discrete view images (one image every $5.8^{\circ}$ ) were acquired over $180^{\circ} .{ }^{21}$ Each image was acquired for $30 \mathrm{~s}$ for a total acquisition time of 16 minutes. Contiguous transaxial tomograms were reconstructed into $12 \mathrm{~mm}$ thick multiple sections by a filtered back projection method using a convolution algorithm ${ }^{1721}$ without attenuation correction. Thereafter, the tomographic images along the short and long axes of the heart were reorganised from the set of transaxial tomograms according to the method described by Borrello et al. ${ }^{22}$ Each reconstructed section contained 150000 to 200000 counts. The reconstructed images were displayed in a $64 \times 64$ matrix (Fig. 1).

All planar and tomographic images were interpreted qualitatively and independently by two experienced observers unaware of the clinical findings. A perfusion defect was defined as a discrete region of absent or decreased thallium-201 activity, present in at least two views of the planar images and at least two sections of the tomographic images. In eight cases in the planar study and in four in the tomographic study there was observer disagreement and a consensus was reached.

Sensitivity was calculated as the number of true positives divided by the number of true positives plus false negatives multiplied by $100(\%)$. Specificity was calculated as the number of true negatives divided by the number of false positives plus true negatives multiplied by $100(\%)$. The sensitivity and specificity of the two techniques was compared using McNemar's test. $\chi^{2}$ analysis was used to determine the significance of differences between the groups. A p value of $<0.05$ was considered to be significant.

\section{Results}

\section{SITE AND EXTENT OF INFARCTION}

Of the 160 patients with infarction, the electrocardiographic site of transmural infarction was anterior in 85 and inferior in 60. Fifteen patients had nontransmural infarction. The extent of the myocardial necrosis estimated by the peak creatine kinase value ranged from 175 to $6469 \mathrm{IU} / 1$ (Fig. 2). These values ranged from 180 to $6469 \mathrm{IU} / 1$ among the 85 patients with anterior myocardial infarction, from 175 to 3706 IU/l among the 60 with inferior infarction, and from 178 to $1180 \mathrm{IU} / \mathrm{l}$ among the 15 with non-transmural infarction. Overall, the peak creatine kinase value was $\leqslant 1000 \mathrm{IU} / 1$ in 63 patients (27 with anterior, 24 with
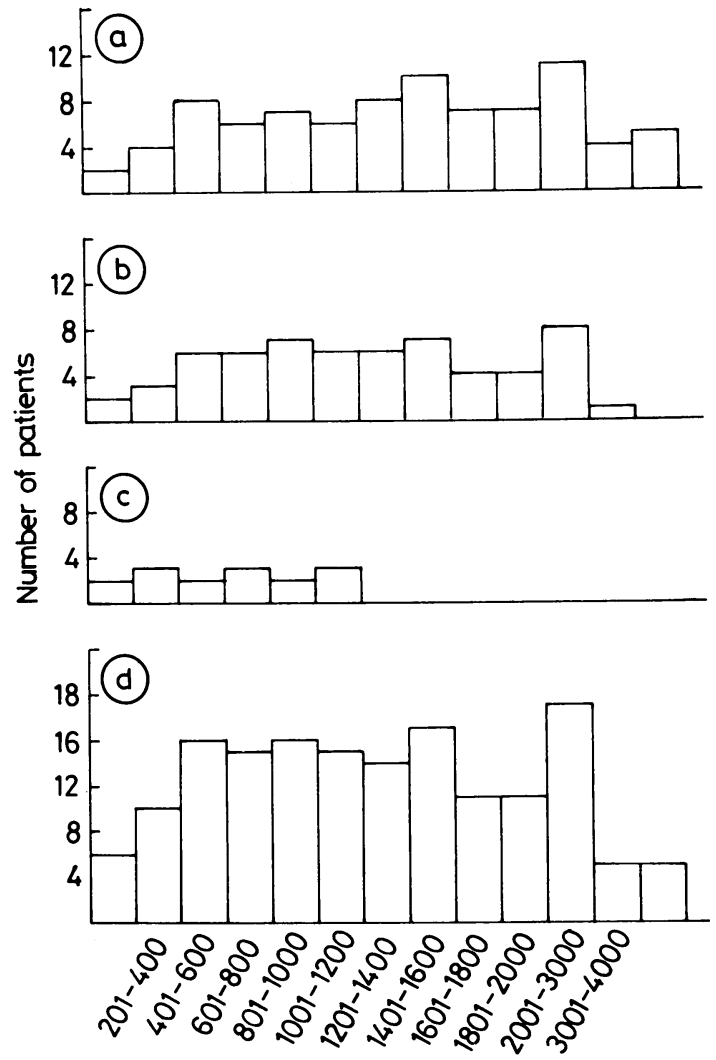

Peak creatine kinase value (IU/I)

Fig. 2 Distribution of infarctions according to size (peak creatine kinase value) and location among 160 patients with myocardial infarction: (a) anterior, (b) inferior, and (c) non-transmural infarctions, and (d) all patients.

inferior, and 12 with non-transmural infarction) and $>1000 \mathrm{IU} / 1$ in the remaining 97 patients (58 with anterior, 36 with inferior, and three with nontransmural infarction).

THALLIUM-201 MYOCARDIAL SCINTIGRAPHY

The results of both planar imaging and tomography are given in Tables 1 and 2. In 125 of $160(78 \%)$

Table 1 Results of planar imaging and tomography with thallium-201 in 160 patients with and 39 patients without myocardial infarction. Figures are numbers (\%) of patients

\begin{tabular}{lccl}
\hline & $\begin{array}{l}\text { Planar } \\
\text { imaging }\end{array}$ & Tomography & Significance \\
\hline Sensitivity: & & & \\
$\quad$ Anterior & $74 / 85(87)$ & $82 / 85(96)$ & $\mathrm{p}<0.02$ \\
Inferior & $44 / 60(73)$ & $58 / 60(97)$ & $\mathrm{p}<0.001$ \\
Non-transmural & $7 / 15(47)$ & $13 / 15(87)$ & $\mathrm{p}<0.05$ \\
Overall & $125 / 160(78)$ & $153 / 160(96)$ & $\mathrm{p}<0.001$ \\
Specificity & $36 / 39(92)$ & $36 / 39(92)$ & $\mathrm{NS}$ \\
\hline
\end{tabular}


Table 2 Detection of myocardial infarction with respect to the location, type, and size of infarction. Figures are numbers (\%) of patients

\begin{tabular}{|c|c|c|c|}
\hline $\begin{array}{l}\text { Location and } \\
\text { peak } C K \text { value }(I U / l)\end{array}$ & Planar imaging & Tomography & Significance \\
\hline $\begin{array}{r}\text { Anterior } \\
\leqslant 1000 \\
\geqslant 1001\end{array}$ & $\begin{array}{l}16 / 27(59) \\
58 / 58(100)\end{array}$ & $\begin{array}{l}24 / 27(89) \\
58 / 58(100)\end{array}$ & $\begin{array}{l}\mathrm{p}<0.02 \\
\mathrm{NS}\end{array}$ \\
\hline $\begin{array}{l}\text { Inferior } \\
\leqslant 1000 \\
\geqslant 1001\end{array}$ & $\begin{array}{c}8 / 24(33) \\
36 / 36(100)\end{array}$ & $\begin{array}{l}22 / 24(92) \\
36 / 36(100)\end{array}$ & $\begin{array}{l}\mathrm{p}<0.001 \\
\mathrm{NS}\end{array}$ \\
\hline $\begin{array}{l}\text { Non-transmural } \\
\quad \leqslant 1000 \\
\geqslant 1001\end{array}$ & $\begin{array}{l}4 / 12(33) \\
3 / 3(100)\end{array}$ & $\begin{array}{c}10 / 12(83) \\
3 / 3(100)\end{array}$ & $\begin{array}{l}\mathrm{p}<0.05 \\
\text { NS }\end{array}$ \\
\hline $\begin{array}{l}\text { Overall } \\
\quad \leqslant 1000 \\
\geqslant 1001\end{array}$ & $\begin{array}{l}28 / 63(44) \\
97 / 97(100)\end{array}$ & $\begin{array}{l}56 / 63(89) \\
97 / 97(100)\end{array}$ & $\begin{array}{l}\mathrm{p}<0.001 \\
\text { NS }\end{array}$ \\
\hline
\end{tabular}

CK, creatine kinase.

patients with myocardial infarction, perfusion defects were detected by both planar imaging and tomography. In 28 of 160 (18\%) patients perfusion defects were identified only by tomography. In seven patients, both planar imaging and tomography were normal. In no patient were defects detected by planar imaging and not by tomography. Overall sensitivity in detecting myocardial infarction was 125 of $160(78 \%)$ by planar imaging and 153 of $160(96 \%)$ by tomography $(p<0.001)$. In the 39 patients without myocardial infarction, all but three patients were correctly identified as normal by each technique. These three patients had an apical defect on both planar and tomographic images. Specificity was thus $92 \%$ for both planar imaging and tomography.

Table 1 also shows the sensitivities of scintigraphy with respect to the electrocardiographic location and type of infarction. Planar imaging less commonly detected inferior or non-transmural infarcts than anterior infarcts $(p<0.05)$, whereas tomography significantly improved the detection of infarcts independent of the location and type of infarction. The increased sensitivity of tomography was, however, confined to the detection of small infarcts as assessed by the peak creatine kinase value (Table 2). In 97 patients with a peak creatine kinase value $>1000 \mathrm{IU} / \mathrm{l}$, sensitivity was $100 \%$ for both techniques. In 63 patients with a peak creatine kinase of $\leqslant 1000 \mathrm{IU} /$, by contrast, sensitivity was only $44 \%$ for planar imaging and $89 \%$ for tomography $(p<0.001$ ) (Table 3 ).

In all cases, the sites of perfusion defects were concordant when present in both planar and tomographic studies and corresponded closely with the electrocardiographic location.

Fig. 3 illustrates the case of a patient with inferior myocardial infarction in whom the planar images were normal. The tomographic study, however, showed a definite inferior perfusion defect, seen best on the short axial and long axial images.

\section{Discussion}

With planar imaging, numerous studies have reported the ability of thallium-201 myocardial scintigraphy to evaluate patients with myocardial infarction. 3710 Good qualitative relations have been found between the location of thallium-201 perfusion defects and evidence of myocardial infarction by electrocardiography, ${ }^{3}$ ventriculography, ${ }^{28}$ coronary angiography, ${ }^{46}$ cardiac enzymes, ${ }^{23}$ and postmortem studies. ${ }^{24}$ Sensitivity in acute myocardial infarction has been reported by Wackers et al to be $100 \%$ within the first six hours, $76 \%$ within 24 hours, and $73 \%$ after 48 hours. ${ }^{7}$ Ritchie et al found sensitivities of $85 \%$ within the first seven days and of $70 \%$ after that period. ${ }^{3}$ This reduction in the sensitivity with increasing time from the onset of myocardial infarction may be related to a decrease in defect size due to the resolution of ischaemia around a small area of infarction. ${ }^{37}$

Because in this study we aimed to detect residual myocardial scarring rather than ischaemia, these studies were performed at rest in stable patients four weeks after the onset of infarction, when ischaemia would not play a large role. The overall sensitivity and specificity of planar imaging were $78 \%$ and $92 \%$ respectively (Table 1). These results are in good agreement with the findings of other workers. ${ }^{367} \mathrm{We}$

Table 3 Results of planar imaging and tomography with thallium-201 in 63 patients with a peak creatine kinase value of $\leqslant 1000$ IU/l. Figures are numbers (\%) of patients

\begin{tabular}{lcc}
\hline Peak CK value $(I U / l)$ & Planar imaging & Tomography \\
\hline$\leqslant 200$ & $0 / 6(0)$ & $3 / 6(50)$ \\
$201-400$ & $1 / 10(10)$ & $7 / 10(70)$ \\
$401-600$ & $7 / 16(44)$ & $15 / 16(94)$ \\
$601-800$ & $8 / 15(53)$ & $15 / 15(100)$ \\
$801-1000$ & $12 / 16(75)$ & $16 / 16(100)$ \\
Total & $28 / 63(44)$ & $56 / 63(89)$ \\
\hline
\end{tabular}

$\mathrm{Ck}$, creatine kinase. 


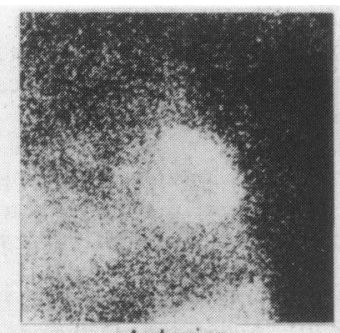

Anterior

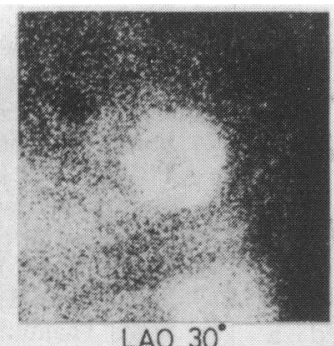

LAO $30^{\circ}$

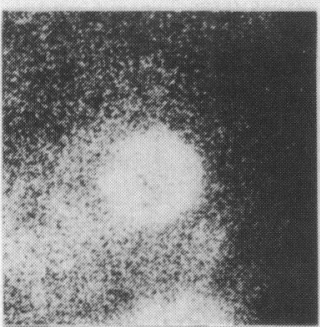

(a)

LAO $45^{\circ}$
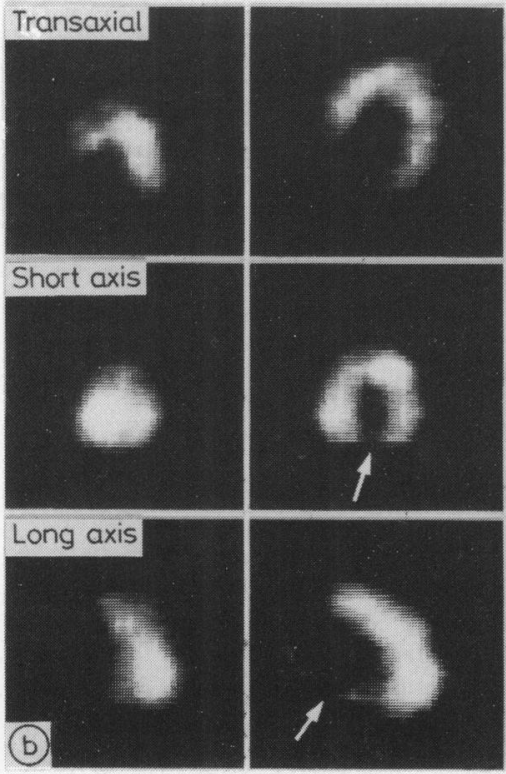

LAO $60^{\circ}$
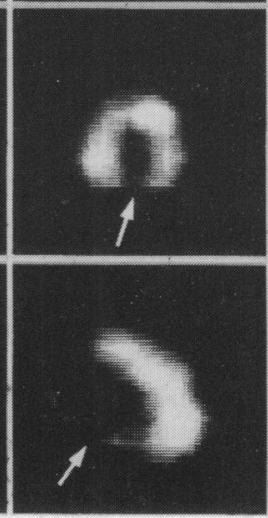
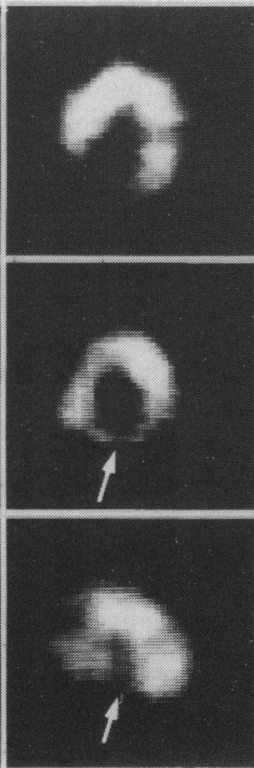

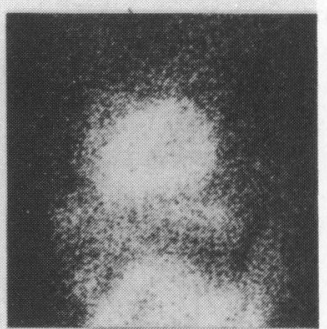

Left lateral
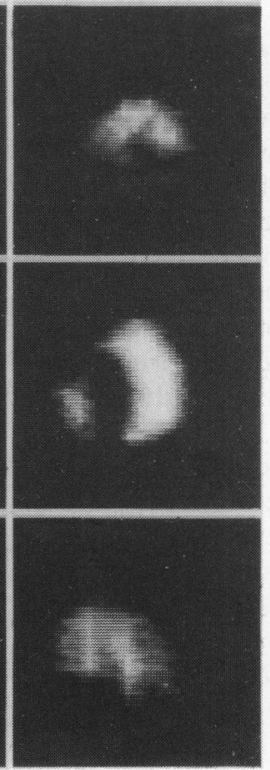

Fig. 3 (a) Planar images and (b) tomograms in a patient with inferior myocardial infarction. No apparent perfusion defects were identified on the planar images. The tomograms showed a definite inferior defect (arrows), seen best on the short axis and long axis images. $L A O$, left anterior oblique. also found that a significant incidence of false negative results in patients with a small infarct accounted for the unsatisfactory sensitivity of planar imaging (Tables 2 and 3).

In planar imaging, background or non-myocardial activity overlaps myocardium, and some normal myocardium from an adjacent or opposing myocardial wall is partly superimposed on a given regional defect.
These may mask the presence of perfusion defects. Experimental studies by Mueller et al showed that a minimum of $5 \mathrm{~g}$ of myocardium must be affected in an abnormal thallium-201 uptake for a defect to be visualised on a planar image. ${ }^{9}$ Clinically, Niess et al showed that generally $6 \%$ or more of the left ventricle must be damaged to be detected on a planar image at rest. ${ }^{10}$ When all these findings, including those of the 
present study, are taken together thallium-201 planar imaging appears to be of limited value as a diagnostic tool in patients with myocardial infarction if the studies are not performed soon after infarction.

Tomographic imaging, although offering no intrinsic improvement of spatial resolution by itself, can help to detect small areas of ischaemia by avoiding the effects of activity from surrounding structures and by increasing contrast between normal and infarcted myocardium. ${ }^{25} 26$ Indeed, tomography showed a significant improvement in detecing small infarcts as assessed by the serum enzyme values independent of the location and type of infarction (Tables 2 and 3). Our equipment can reorganise not only transaxial tomograms but also short axial and long axial tomograms, which greatly helped the accurate assessment of radionuclide distribution (Fig. 3). As a result, tomography yielded a higher overall sensitivity than planar imaging in the detection of infarction without significant loss of specificity (Table 1). This improvement is of clinical importance because the diagnosis or exclusion of myocardial infarction is a common and sometimes difficult problem in clinical practice.

In addition to its diagnostic value, thallium-201 scintigraphy provides prognostic information. 2728 Moreover, this technique has been recently used for assessing the effect of intracoronary thrombolysis on myocardial salvage. ${ }^{2930}$ Another advantage of tomography is in improving the quantification of the extent of perfusion abnormalities as reported previously. ${ }^{17}$ Although cardiac motion and attenuation corrections are still problems that prevent accurate quantification, tomography can provide more detailed information of the changes in myocardial perfusion resulting from therapeutic interventions.

The relatively short data collection time allows this tomographic approach to be applied to transient perfusion abnormalities induced by exercise. Tomography might be expected to increase the accuracy of thallium-201 imaging to detect individual coronary artery involvement and even less pronounced coronary artery disease. But this subject requires further study.

\section{References}

1 Wackers FJT, Schoot JB, Sokole EB, et al. Noninvasive visualization of acute myocardial infarction in man with thallium-201. Br Heart $\mathcal{F}$ 1975; 37: 741-4.

2 Hamilton GW, Trobaugh GB, Ritchie JL, Williams DL, Weaver WD, Gould KL. Myocardial imaging with intravenously injected thallium-201 in patients with suspected coronary artery disease: analysis of technique and correlation with electrocardiographic, coronary anatomic and ventriculographic findings. Am F Cardiol 1977; 39: 347-54.
3 Ritchie JL, Zaret BL, Strauss HW, et al. Myocardial imaging with thallium-201: a multicenter study in patients with angina pectoris or acute myocardial infarction. Am F Cardiol 1978; 42: 345-50.

4 Bailey IK, Griffith LSC, Rouleau J, Strauss HW, Pitt B. Thallium-201 myocardial perfusion imaging at rest and during exercise: comparative sensitivity to electrocardiography in coronary artery disease. Circulation 1977; 55: 79-87.

5 Botvinick EH, Taradash MR, Shames DM, Parmley WW. Thallium-201 myocardial perfusion scintigraphy for the clinical clarification of normal, abnormal and equivocal electrocardiographic stress tests. Am $\mathcal{F}$ Cardiol 1978; 41: 43-51.

6 Kambara H, Ishii Y. Thallium-201 myocardial scintigraphy: quantification and its image processing. Fpn Circ $\mathcal{F}$ 1981; 45: 120-6.

7 Wackers FJT, Sokole EB, Samson HG, et al. Value and limitations of thallium-201 scintigraphy in the acute phase of myocardial infarction. $N$ Engl 7 Med 1976; 295: $1-5$.

8 Uthurralt N, Parodi O, Severi S, Davies G, Maseri A. Thallium-201 scintigraphy for diagnosis of old myocardial infarction: comparison with electrocardiographic, ventriculographic, and coronary arteriographic findings. Br Heart f 1980; 43: 527-34.

9 Mueller TM, Marcus ML, Ehrhardt JC, Chaudhuri T, Abboud FM. Limitations of thallium-201 myocardial perfusion scintigrams. Circulation 1976; 54: 640-6.

10 Niess GS, Logic JR, Russell RO Jr, Rackley CE, Rogers WJ. Usefulness and limitations of thallium-201 myocardial scintigraphy in delineating location and size of prior myocardial infarction. Circulation 1979; 59: 1010-9.

11 Budinger TF. Physical attributes of single-photon tomography. F Nucl Med 1980; 21: 579-92.

12 Murphy PH, Thompson WL, Moore ML, Burdine JA. Radionuclide computed tomography of the body using routine radiopharmaceuticals. I. System characterization. 7 Nucl Med 1979; 20: 102-7.

13 Williams DL, Ritchie JL, Harp GD, Caldwell JH, Hamilton GW. In vivo simulation of thallium-201 myocardial scintigraphy by seven-pinhole emission tomography. 7 Nucl Med 1980; 21: 821-8.

14 Tamaki N, Mukai T, Ishii Y, et al. Clinical evaluation of thallium-201 emission myocardial tomography using a rotating gamma camera: comparison with seven-pinhole tomography. F Nucl Med 1981; 22: 849-55.

15 Maublant J, Cassagnes J, Le Jeune JJ, et al. A comparison between conventional scintigraphy and emission tomography with thallium-201 in the detection of myocardial infarction: concise communication. $\mathcal{F ~ N u c l}$ Med 1982; 23: 204-8.

16 Ritchie JL, Williams DL, Harp G, Stratton JL, Caldwell JH. Transaxial tomography with thallium-201 for detecting remote myocardial infarction. Comparison with planar imaging. Am $\mathcal{F}$ Cardiol 1982; 50: 1236-41.

17 Tamaki S, Nakajima H, Murakami T, et al. Estimation of infarct size by myocardial emission computed tomography with thallium-201 and its relation to creatine kinase-MB release after myocardial infarction in man. Circulation 1982; 66: 994-1001.

18 Sammel NL, Stuckey JG, Brandt PWT, Norris RM. 
Comparison of enzymic with cineangiocardiographic estimations of myocardial infarct size. Br Heart $\mathcal{F} 1980$; 43: 609-16.

19 Ryan W, Karliner JS, Gilpin EA, Covell JW, DeLuca $M$, Ross J Jr. The creatine kinase curve area and peak creatine kinase after acute myocardial infarction: usefulness and limitations. Am Heart $\mathcal{F}$ 1981; 101: 162-8.

20 Austen WG, Edwards JE, Frye RL, et al. A reporting system on patients evaluated for coronary artery disease. Report of the Ad Hoc Committee for grading of coronary artery disease, Council on Cardiovascular Surgery, American Heart Association. Circulation 1975; 51(suppl): 5-40.

21 Tamaki N, Mukai T, Ishii Y, et al. Comparative study of thallium emission myocardial tomography with $180^{\circ}$ and $360^{\circ}$ data collection. $\mathrm{F} \mathrm{Nucl} \mathrm{Med} \mathrm{1982;} \mathrm{23:} \mathrm{661-6.}$

22 Borrello JA, Clinthorne NH, Rogers WL, Thrall JH, Keyes JW Jr. Oblique-angle tomography: a restructing algorithm for transaxial tomographic data. $\mathrm{F} \mathrm{Nucl} \mathrm{Med}$ 1981; 22: 471-3.

23 Henning H, Schelbert HR, Righetti A, Ashburn WL, O'Rourke RA. Dual myocardial imaging with technetium-99m pyrophosphate and thallium-201 for detecting, localizing and sizing acute myocarial infarction. Am f Cardiol 1977; 40: 147-55.

24 Wackers FJT, Becker AE, Samson G, et al. Location and size of acute transmural myocardial infarction esti- mated from thallium-201 scintiscans: a clinicopathological study. Circulation 1977; 56: 72-8.

25 Ritchie JL, Larsson S, Israelson A, et al. Single photon tomographic imaging of a standard heart phantom with ${ }^{201} \mathrm{Tl}$ : a gamma camera based system. Eur $\mathcal{F} \mathrm{Nucl}$ Med 1982; 7: 254-9.

26 Jaszczak RJ, Whitehead FR, Lim CB, Coleman RE. Lesion detection with single-photon emission computed tomography (SPECT) compared with conventional imaging. F Nucl Med 1982; 23: 97-102.

27 Silverman KJ, Becker LC, Bulkley BH, et al. Value of early thallium-201 scintigraphy for predicting mortality in patients with acute myocardial infarction. Circulation 1980; 61: 996-1003.

28 Perez-Gonzalez J, Botvinick EH, Dunn R, et al. The late prognostic value of acute scintigraphic measurement of myocardial infarction size. Circulation 1982; 66: 960-71.

29 Schuler G, Schwarz F, Hofmann M, et al. Thrombolysis in acute myocardial infarction using intracoronary streptokinase: assessment by thallium-201 scintigraphy. Circulation 1982; 66: 658-64.

30 Tamaki S, Murakami T, Kadota $\mathrm{K}$, et al. Effects of coronary artery reperfusion on relation between creatine kinase-MB release and infarct size estimated by myocardial emission tomography with thallium-201 in man. $\mathcal{F}$ Am Coll Cardiol 1983; 2: 1031-8. 